\title{
ESTIMATION OF BIOMASS CARBON STOCKS OVER PEAT SWAMP FORESTS USING MULTI-TEMPORAL AND MULTI-POLARIZATIONS SAR DATA
}

\author{
Arief Wijaya $^{(\mathrm{a})^{*}}$, Veraldo Liesenberg ${ }^{(\mathrm{b})}$, Ari Susanti ${ }^{(\mathrm{c})}$, Oka Karyanto $^{(\mathrm{c})}$ and Louis V. Verchot ${ }^{(\mathrm{a})}$ \\ ${ }^{\text {a }}$ Center for International Forestry Research, Situ Gede, Bogor Barat 16115, Indonesia \\ ${ }^{\mathrm{b}}$ Universidade Estadual de Santa Catarina (UDESC), Centro de Ciências Agroveterinárias (CAV), Santa Catarina, Brasil \\ ${ }^{\mathrm{c}}$ Faculty of Forestry, Gadjah Mada University, J1. Sosio Yustisia, Bulaksumur, Yogyakarta, 55281, Indonesia \\ ${ }^{*}$ Corresponding author: a.wijaya@,cgiar.org
}

THEME: Forests, Biodiversity and Terrestrial Ecosystems (BIOD theme).

\begin{abstract}
:
The capability of L-band radar backscatter to penetrate through the forest canopy is useful for mapping the forest structure, including above ground biomass (AGB) estimation. Recent studies confirmed that the empirical AGB models generated from the L-band radar backscatter can provide favourable estimation results, especially if the data has dual-polarization configuration. Using dual polarimetry SAR data the backscatter signal is more sensitive to forest biomass and forest structure because of tree trunk scattering, thus showing better discriminations of different forest successional stages. These SAR approaches, however, need to be further studied for the application in tropical peatlands ecosystem We aims at estimating forest carbon stocks and stand biophysical properties using combination of multi-temporal and multi-polarizations (quad-polarimetric) L-band SAR data and focuses on tropical peat swamp forest over Kampar Peninsula at Riau Province, Sumatra, Indonesia which is one of the most peat abundant region in the country.

Applying radar backscattering (Sigma nought) to model the biomass we found that co-polarizations (HH and VV) band are more sensitive than cross-polarization channels (HV and VH). Individual $\mathrm{HH}$ polarization channel from April 2010 explained $>86 \%$ of AGB. Whereas VV polarization showed strong correlation coefficients with LAI, tree height, tree diameter and basal area. Surprisingly, polarimetric anisotropy feature from April 2007 SAR data show relatively high correlations with almost all forest biophysical parameters. Polarimetric anisotropy, which explains the ratio between the second and the first dominant scattering mechanism from a target has reduced at some extent the randomness of scattering mechanism, thus improve the predictability of this particular feature in estimating the forest properties. These results may be influenced by local seasonal variations of the forest as well as moisture, but available quad-pol SAR data were unable to show these patterns, since all the SAR data were acquired during the rainy season.

The results of multi-regression analysis in predicting above ground biomass shows that ALOS PALSAR data acquired in 2010 has outperformed other time series data. This is probably due to the fact that land cover change in the area from $2007-2009$ was highly dynamic, converting natural forests into rubber and Acacia plantations, thus SAR data of 2010 which was acquired in between of two field campaigns has provided significant results $(\mathrm{F}=40.7, \mathrm{P}<0.005)$. In general, we found that polarimetric features have improved the models performance in estimating AGB. Surprising results come from single HH polarization band from April 2010 that has a strong correlation with AGB $(\mathrm{r}=0.863)$. Also, HH polarization band of 2009 SAR image resulted in a moderate correlation with AGB $(r=0.440)$.
\end{abstract}

Keywords: forest carbon biomass, ALOS Palsar, SAR, polarimetric features

\section{INTRODUCTION}

In the context of reducing emissions from deforestation and forest degradation, provision of reliable forest carbon stocks information is urgently needed to help reducing anthropogenic greenhouse gas emissions. Total amount of global emissions from deforestation and forest degradation, and peatland fires is determined to be about $15 \%$ of global anthropogenic $\mathrm{CO}_{2}$ emissions from 1997 to 2007 (van der Werf et al., 2009). Tropical forests cover approximately $15 \%$ of the Earth's land surface (Wijaya et al., 2010) and contain up to $40 \%$ of the terrestrial carbon (Page et al., 2002). One type of tropical forest ecosystem is the peat swamp or peatland forest. Peatland ecosystem has an important role as carbon sink that stores huge amounts of carbon. Within the context of global climate change, there has been an increased interest in tropical peatlands because of their importance as carbon stores and their role in carbon fluxes (Jaenicke et al., 2008; Page et al., 2002; Rieley and Page, 2005). Although peatlands cover only $3 \%$ of the Earth's land surface, they contain as much carbon as all terrestrial biomass, twice as much as all global forest biomass, and about the same that can be found in the atmosphere. Peatlands store carbon for thousands of years and play critical role in biodiversity conservation and hydrological regulation (van Beukering et al., 2008).

Application of microwave remote sensing for biomass estimation allows for the provision of additional information to supplement ground measurements, since they are usually insensitive to the cloud-free daylight conditions required for image acquisition with other platforms, like Landsat. The application of SAR data for mapping of tropical forest 
properties has been widely applied (Fransson and Israelsson, 1999; Hajnsek et al., 2005; Isola and Cloude, 2001; Kuplich et al., 2005; Luckman et al., 1996), but few studies found applying this data in tropical peatlands. Besides, empirical models of microwave instrument data are known to be very sensitive to the density, shape, length, dielectric properties, and orientation of the scatterers (Kingsley and Quegan, 1992). The X-band (2.4 $3.75 \mathrm{~cm})$ SAR data is useful for terrain mapping and for discriminating the top canopy of vegetated lands. Some studies have shown that the utility of single polarization C-band data $(3.75-7.5 \mathrm{~cm})$ may bring some limitations for distinguishing biomass in regenerating forests and deforested areas, because the radar backscatter becomes insensitive especially if the soil is dry and the influence of water is minimized (Saatchi et al., 1997). In contrast, L-band SAR data $(15-30 \mathrm{~cm})$ showed good ability for modeling the forest parameters under dense vegetation (Luckman et al., 1997; Rauste, 2005). The capability of L-band radar backscatter to penetrate through the forest canopy makes this data useful for mapping the forest structure, including above ground biomass (AGB) estimation (Luckman et al., 1997). Recent studies confirmed that the empirical AGB models generated from the L-band radar backscatter can provide favourable estimation results, especially if the data has dualpolarization configuration. Using dual polarimetry SAR data the backscatter signal is more sensitive to forest biomass and forest structure because of tree trunk scattering, thus showing better discriminations of different forest successional stages (Ranson et al., 1997; Saatchi et al., 1997). This study aims at estimating forest carbon stocks and some stand biophysical properties using combination of multi-temporal and multi-polarizations (quad-polarimetric) L-band SAR data.

\section{DATA AND METHODS}

\subsection{Title}

This work focuses on tropical peat swamp forest over Kampar Peninsula at Riau Province, Sumatra, Indonesia (Figure 1). The Kampar Peninsular forest represents the second largest tropical peatland in Indonesia after Central Kalimantan Province. Peatland conversion into Acacia crassicarpa plantation for pulp and paper industries and excessive expansion of oil palm plantation are the major threats for this particular ecosystem. During the last decade, deforestation in the Riau Province is among the highest in the whole country, as a trade off of accelerating local economic growth. In this study, 83 sampling plot data (red circle in Figure 1) have been collected during dry season in $2009-2010$.

We used quad-polarimetric SAR (PLR) data from ALOS satellite for the purpose of the study. Four scenes of ALOS Palsar data acquired in April 2007, May 2007, April 2009 and April 2010 during rainy season were considered for this study. SAR image pre-processing steps include image co-registration, and radiometric calibration and normalizations, image geocoding and multi-temporal speckle filtering applying Enhanced Lee algorithm. Using covariance matrices, polarimetric SAR features were calculated, namely polarimetric alpha angle, entropy and anisotropy. Attempts to estimate carbon stocks applied mono-temporal and multi-temporal approaches (e.g $\mathrm{HH}_{\mathrm{t} 1} \mathrm{vs} \mathrm{H}_{\mathrm{t} 2}$, etc), also combining different polarizations (e.g $\mathrm{HH}_{\mathrm{t} 1}+\mathrm{HV}_{\mathrm{t} 1}+\mathrm{VH}_{\mathrm{t} 1}+\mathrm{VV}_{\mathrm{t} 1} \mathrm{vs} \mathrm{H}_{\mathrm{t} 2}+\mathrm{HV}_{\mathrm{t} 2}+\mathrm{VH}_{\mathrm{t} 2}+\mathrm{VV}_{\mathrm{t} 2}$ ).

Polarimetric SAR features are used as additional predictors of AGB to study their effectiveness on the model's performance.

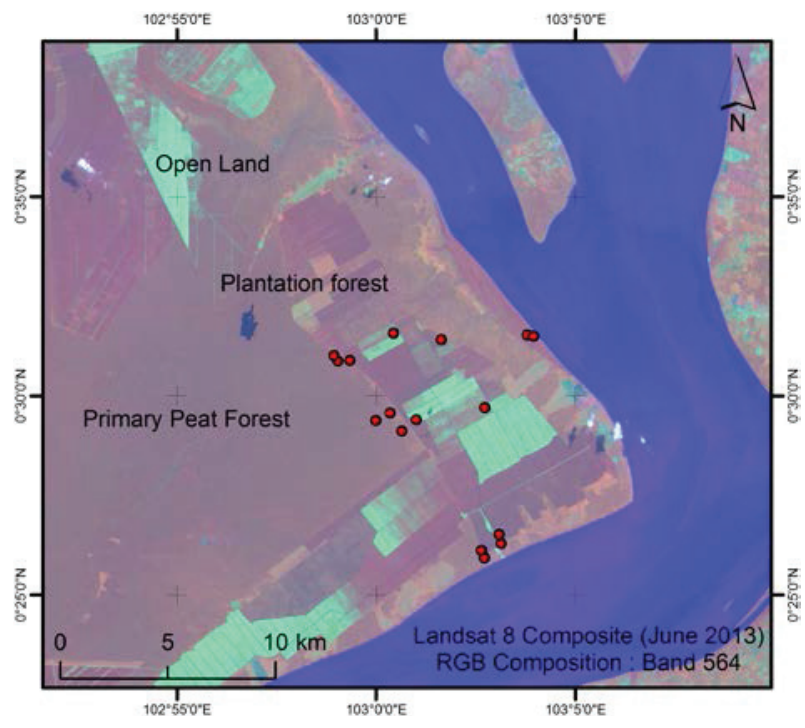

Figure 1 sampling distribution over the study area

\section{RESULTS AND DISCUSSION}

\subsection{Field data}

Various parameters, namely diameter at breast height (DBH), basal area, tree height, canopy coverage and leaf area index (LAI) have been measured. Furthermore, allometric equations were applied to estimate tree volume and biomass, hence converted into carbon stocks. The sample plots were measured over peat swamp forest, pioneer species (Macaranga sp.), mangrove forest, plantation forest (A. crassicarpa $s p$.) and rubber (Hevea brasilensis) plantation (Table 1). Sampling plots showing the properties of peat swamp forests (PSF) and successional plantation forests (PF) explain the increasing of stand volume, biomass, carbon stocks and LAI following forest regenerations stages (from PF1 to PF3, and PSF) (Figure 2).

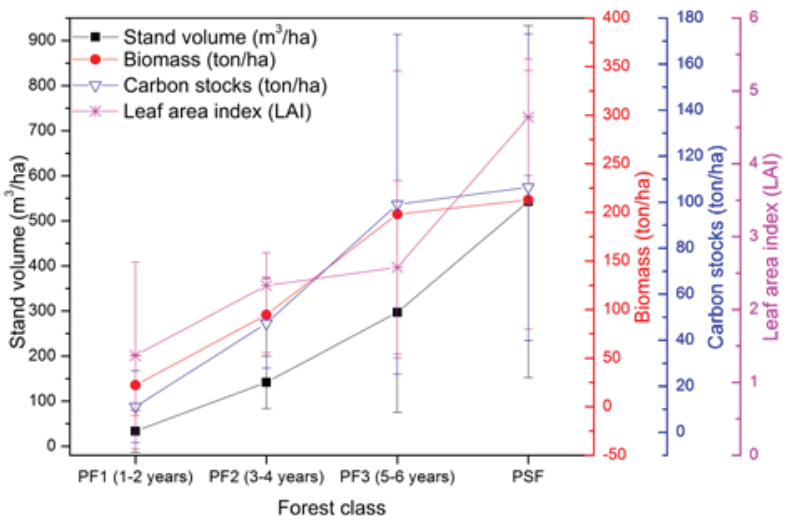

Figure 2 Biophysical parameters of peat swamp forest (PSF) and plantation forest (PF)

\subsection{SAR data analysis}

Applying radar backscattering (Sigma nought) to model the biomass we found that co-polarizations ( $\mathrm{HH}$ and $\mathrm{VV}$ ) band are more sensitive than cross-polarization channels (HV and VH). Individual $\mathrm{HH}$ polarization channel from April 2010 explained $>86 \%$ of AGB. Whereas VV polarization showed strong 
The International Archives of the Photogrammetry, Remote Sensing and Spatial Information Sciences, Volume XL-7/W3, 2015 36th International Symposium on Remote Sensing of Environment, 11-15 May 2015, Berlin, Germany

Table 1 Carbon stocks and biophysical properties over sampled areas

\begin{tabular}{l|cccccc}
\hline Landuse/Landcover & Volume $\left(\mathrm{m}^{3} / \mathrm{ha}\right)$ & AGB $(\mathrm{Mg} / \mathrm{ha})$ & Carbon stocks $(\mathrm{Mg} / \mathrm{ha})$ & Tree height $(\mathrm{m})$ & Basal area $\left(\mathrm{m}^{2}\right)$ & LAI \\
\hline Peat swamp forest & 592.35 & 228.25 & 114.12 & 16.92 & 11.22 & 33.19 \\
Pioneer species & 32.63 & 7.47 & 3.74 & 9.53 & 9.71 & 3.09 \\
(Macaranga sp.) & 182.16 & 105.65 & 52.82 & 12.57 & 11.79 & 2.38 \\
Mangrove forest & 196.33 & 130.95 & 65.48 & 14.95 & 51.02 & 1.32 \\
Plantation forest & 125.73 & 113.44 & 56.72 & 2.06 \\
Rubber plantation & & & & &
\end{tabular}

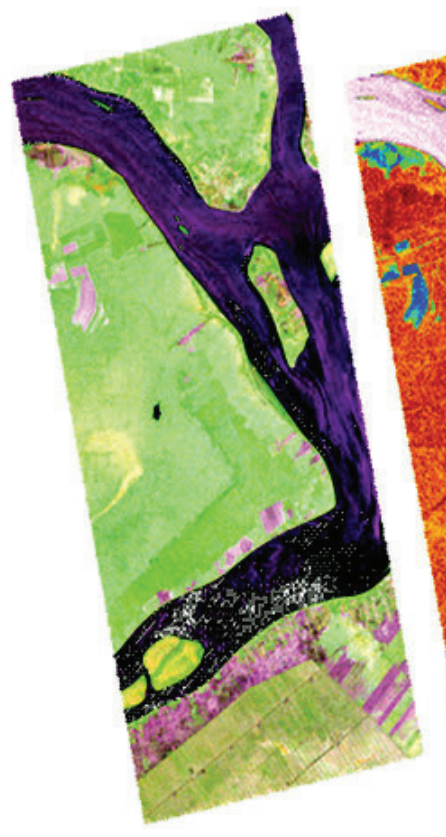

(a)

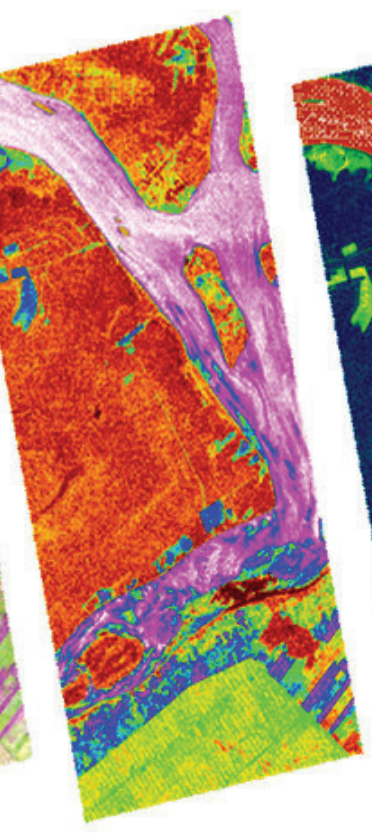

(b)

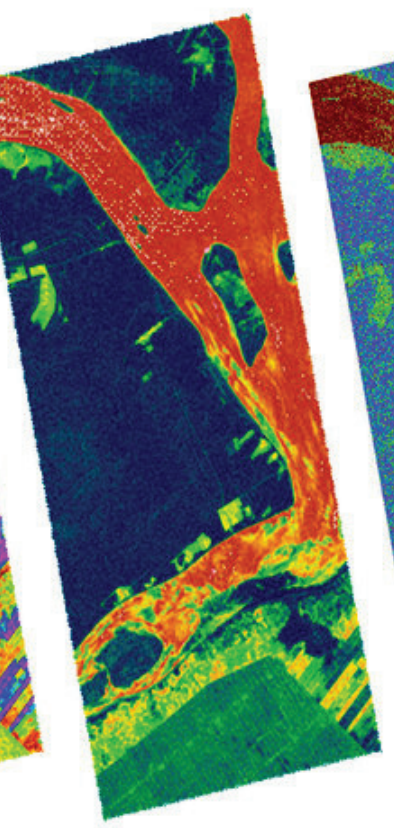

(c)

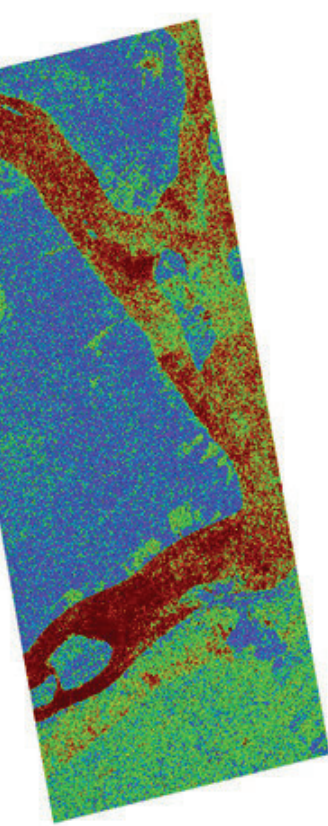

(d)

Figure 2 RGB composite of $\mathrm{HH}, \mathrm{HV}, \mathrm{VV}$ (a), polarimetric alpha (b), polarimetric entropy (c) and polarimetric anisotropy (d)

Table 2 Pearson correlation coefficients $(r)$ of SAR backscattering and polarimetric features with biophysical forest stand parameters. The two highest negative (orange) and positive (pink) correlations between each SAR data and forest stand properties are highlighted.

\begin{tabular}{|c|c|c|c|c|c|c|}
\hline Acquisition date & SAR data & Biomass (Mg/ha) & LAI & Tree height $(\mathrm{m})$ & Diameter $(\mathrm{m})$ & Basal area $\left(\mathrm{m}^{2} / \mathrm{ha}\right)$ \\
\hline \multirow[t]{7}{*}{ April 4, 2007} & 3001_HH & -0.249 & -0.174 & -0.389 & -0.177 & -0.188 \\
\hline & 3001_HV & 0.256 & 0.173 & 0.414 & 0.350 & 0.395 \\
\hline & 3001_VH & 0.278 & 0.198 & 0.429 & 0.374 & 0.410 \\
\hline & 3001_VV & -0.142 & -0.268 & -0.158 & 0.020 & 0.009 \\
\hline & 3001_Alpha & 0.274 & 0.345 & 0.435 & 0.267 & 0.297 \\
\hline & 3001_Entropy & 0.282 & 0.388 & 0.462 & 0.267 & 0.315 \\
\hline & 3001_Anisotropy & -0.579 & -0.413 & -0.630 & -0.542 & -0.557 \\
\hline \multirow[t]{7}{*}{ May 20, 2007} & $7001 \mathrm{HH}$ & 0.021 & -0.348 & 0.010 & 0.269 & 0.185 \\
\hline & 7001_HV & 0.260 & 0.458 & 0.526 & 0.355 & 0.394 \\
\hline & 7001_VH & 0.279 & 0.442 & 0.532 & 0.366 & 0.408 \\
\hline & 7001_VV & -0.031 & -0.067 & 0.186 & 0.336 & 0.330 \\
\hline & 7001_Alpha & 0.251 & 0.416 & 0.414 & 0.262 & 0.304 \\
\hline & 7001_Entropy & 0.259 & 0.434 & 0.433 & 0.264 & 0.309 \\
\hline & 7001_Anisotropy & -0.324 & -0.081 & -0.338 & -0.168 & -0.192 \\
\hline \multirow[t]{7}{*}{ April 9, 2009} & 2001_HH & 0.440 & -0.314 & 0.026 & 0.032 & 0.030 \\
\hline & 2001_HV & 0.193 & 0.371 & 0.295 & 0.186 & 0.152 \\
\hline & 2001_VH & 0.249 & 0.390 & 0.358 & 0.305 & 0.255 \\
\hline & 2001_VV & 0.285 & 0.180 & 0.139 & 0.056 & 0.089 \\
\hline & 2001_Alpha & -0.089 & 0.549 & 0.223 & 0.235 & 0.208 \\
\hline & 2001_Entropy & -0.054 & 0.583 & 0.250 & 0.336 & 0.364 \\
\hline & 2001_Anisotropy & -0.011 & -0.643 & -0.114 & -0.178 & -0.163 \\
\hline \multirow[t]{7}{*}{ April 12, 2010} & 1001_HН & 0.863 & -0.010 & 0.426 & 0.490 & 0.460 \\
\hline & 1001_HV & -0.074 & 0.171 & -0.085 & 0.026 & 0.077 \\
\hline & 1001_VH & -0.078 & 0.159 & -0.088 & 0.030 & 0.077 \\
\hline & 1001_VV & 0.489 & 0.567 & 0.549 & 0.432 & 0.417 \\
\hline & 1001_Alpha & -0.420 & 0.034 & -0.275 & -0.177 & -0.115 \\
\hline & 1001_Entropy & -0.367 & 0.039 & -0.243 & -0.167 & -0.106 \\
\hline & 1001_Anisotropy & 0.074 & -0.051 & 0.175 & -0.083 & -0.086 \\
\hline
\end{tabular}


correlation coefficients with LAI, tree height, tree diameter and basal area. Surprisingly, polarimetric anisotropy feature from April 2007 SAR data show relatively high correlations with almost all forest biophysical parameters. Polarimetric anisotropy, which explains the ratio between the second and the first dominant scattering mechanism from a target has reduced at some extent the randomness of scattering mechanism, thus improve the predictability of this particular feature in estimating the forest properties. These results may be influenced by local seasonal variations of the forest as well as moisture, but available quad-pol SAR data were unable to show these patterns, since all the SAR data were acquired during the rainy season (Figure 3). Also, the study area is a non-seasonal zone, with little precipitation variations between dry and rainy season, which may cause minimum local climate variations.

\subsection{Regression analysis results}

The results of multi-regression analysis in predicting above ground biomass shows that ALOS PALSAR data acquired in 2010 has outperformed other time series data. This is probably due to the fact that land cover change in the area from $2007-$ 2009 was highly dynamic, converting natural forests into rubber and Acacia plantations, thus SAR data of 2010 which was acquired in between of two field campaigns has provided significant results $(\mathrm{F}=40.7, \mathrm{P}<0.005)$. In general, we found that polarimetric features have improved the models performance in estimating AGB. Surprising results come from single $\mathrm{HH}$ polarization band from April 2010 that has a strong correlation with AGB $(r=0.863)$. Also, HH polarization band of 2009 SAR image resulted in a moderate correlation with AGB $(r=0.440)$. The VV polarization of SAR data from 2010, on the other hand, may be used to explain forest parameters in general, given its moderate predictive capability to majority of forest parameters $(r>0.40)$ considered in this research.

Main issues of multi-temporal SAR-biomass modelling, as well as the use of single SAR data is due to high precipitation and high soil moisture conditions. In this study, performance of time series SAR data to estimate AGB is mostly effected by rapid conversion of natural forests into Acacia crassicarpa sp., Eucalyptus $s p$. and oil palm plantations. Insensitivity of SAR data acquired in April 2007 to properly predict AGB is mainly because of such forest land conversion.

\section{CONCLUSION}

This paper tested the predictive ability of multi-temporal SAR data to estimate above ground biomass over tropical peat swamp forests in SE Asia. The co-polarization bands (HH and $\mathrm{VV}$ ) in general are better than cross-polarization data (HV and $\mathrm{VH}$ ) to predict biomass and other tree parameters (i.e. LAI, tree height, diameter and basal area). Addition of polarimetric SAR features, e.g. alpha angle, entropy and anisotropy has improved model's predictability, thus improve the accuracy of biomass estimate and reduce bias.

Given the absence or minimum effects of local seasonal variability, the accuracy and reliability of SAR backscatter models are mainly effected by the stability of land use/forest cover over longer period.

\section{ACKNOWLEDGEMENT}

ALOS/PALSAR scenes were obtained under the Cat.1-Proposal (ID6242) from the ESA's Third Party Mission.

\section{REFERENCES}

Fransson, J.E.S., Israelsson, H., 1999. Estimation of stem volume in boreal forests using ERS-1 C- and JERS-1 L-band SAR data. International Journal of Remote Sensing 20, 123137.

Hajnsek, I., Kugler, F., Papathanassiou, K., Horn, R., Scheiber, R., Moreira, A., Hoekman, D., Davidson, M., 2005. INDREX II - Indonesian airborne radar experiment campaign over tropical forest in $L$ - and P-band: First results, International Geoscience and Remote Sensing Symposium (IGARSS), Seoul, pp. 43354338.

Isola, M., Cloude, S.R., 2001. Forest height mapping using space-borne polarimetric SAR interferometry, International Geoscience and Remote Sensing Symposium (IGARSS), Sydney, NSW, pp. 1095-1097.

Jaenicke, J., Rieley, J.O., Mott, C., Kimman, P., Siegert, F., 2008. Determination of the amount of carbon stored in Indonesian peatlands. Geoderma 147, 151-158.

Kingsley, S., Quegan, S., 1992. Understanding radar systems, 1st Edition ed. SciTech Publishing.

Kuplich, T.M., Curran, P.J., Atkinson, P.M., 2005. Relating $S A R$ image texture to the biomass of regenerating tropical forests. International Journal of Remote Sensing 26, 4829-4854.

Luckman, A., Baker, J., Kuplich, T.M., Corina da Costa, F.Y., Alejandro, C.F., 1997. A study of the relationship between radar backscatter and regenerating tropical forest biomass for spaceborne SAR instruments. Remote Sensing of Environment $60,1-13$.

Luckman, A., Baker, J., Kuplich, T.M., Yanasse, C.d.C.F., Frery, A.C., 1996. A study of the relationship between radar backscatter and regenerating tropical forest biomass for spaceborne SAR instruments. Remote Sensing of Environment 60, 1-13.

Page, S.E., Siegert, F., Rieley, J.O., Boehm, H.-D.V., Jaya, A., Limin, S., 2002. The amount of carbon released from peat and forest fires in Indonesia during 1997. Nature 420, 61-65.

Ranson, K.J., Sun, G., Lang, R.H., Chauhan, N.S., Cacciola, R.J., Kilic, O., 1997. Mapping of boreal forest biomass from spaceborne synthetic aperture radar. Journal of Geophysical Research D: Atmospheres 102, 29599-29610.

Rauste, Y., 2005. Multi-temporal JERS SAR data in boreal forest biomass mapping. Remote Sensing of Environment 97, 263-275.

Rieley, J.O., Page, S.E., 2005. Wise use of Tropical Peatlands: Focus on Southeast Asia, Synthesis of results and conclusions of the UK Darwin Initiative and the EU INCO EUTROP, 
STRAPEAT and RESTORPEAT Partnerships together with proposals for implementing wise use of tropical peatlands. ALTERRA - Wageningen University and Research Centre and the EU INCO - STRAPEAT and RESTORPEAT Partnerships, Wageningen, The Netherlands, p. 266pp.

Saatchi, S.S., Soares, J.V., Alves, D.S., 1997. Mapping deforestation and land use in amazon rainforest by using SIR-C imagery. Remote Sensing of Environment 59, 191-202.

van Beukering, P.J.H., Schaafsma, M., Davies, O., Oskolokaite, I., 2008. The economic value of peatland resources within the Central Kalimantan Peatland Project in Indonesia: Perceptions of local communities. Central Kalimantan Peatlands Project. Institute for Environmental Studies, Vrije Universiteit, Amsterdam, The Netherlands, p. 85pp.

van der Werf, G.R., Morton, D.C., DeFries, R.S., Olivier, J.G.J., Kasibhatla, P.S., Jackson, R.B., Collatz, G.J., Randerson, J.T., 2009. CO2 emissions from forest loss. Nature Geosci 2, 737 738.

Wijaya, A., Liesenberg, V., Gloaguen, R., 2010. Retrieval of forest attributes in complex successional forests of Central Indonesia: Modeling and estimation of bitemporal data. Forest Ecology and Management 259, 2315-2326. 


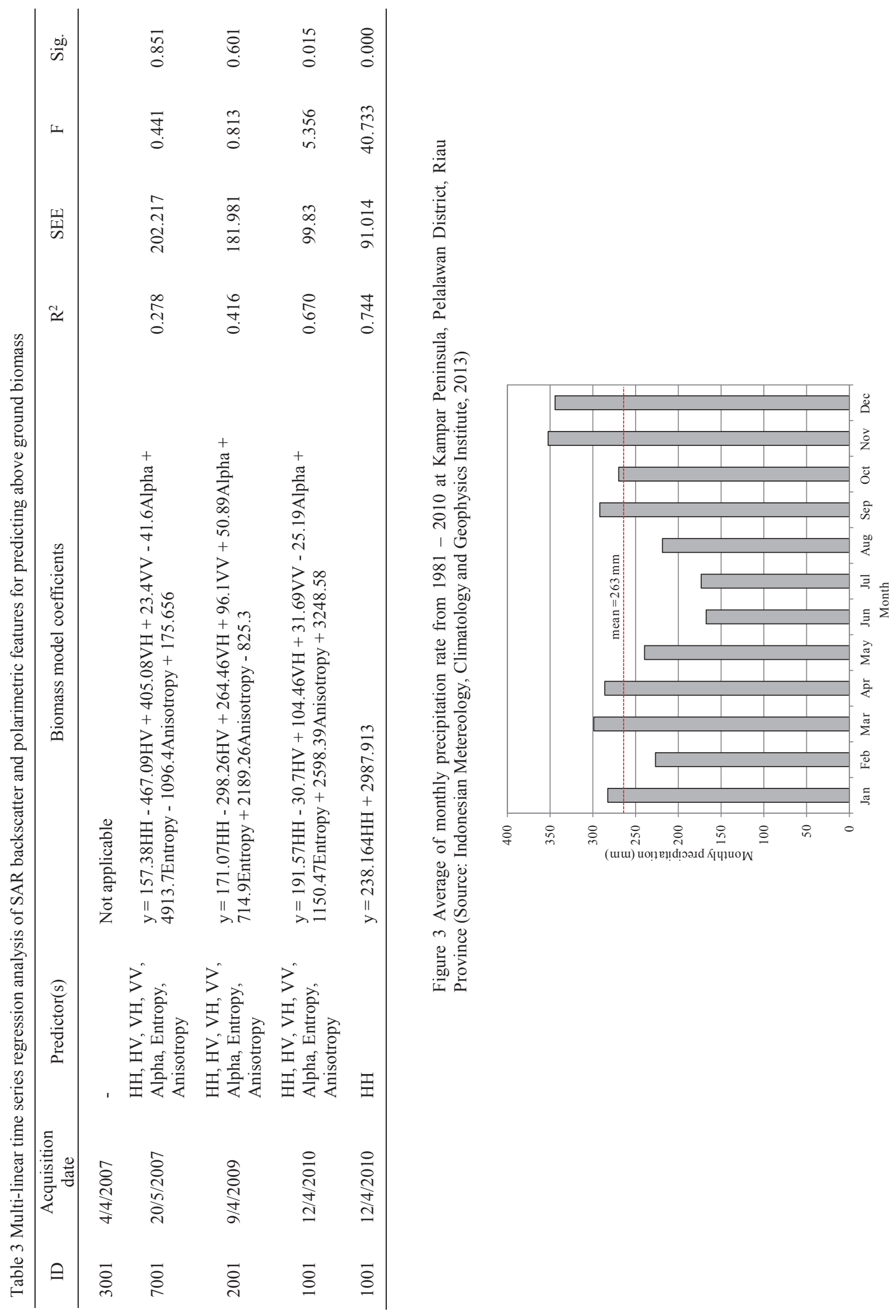

